\title{
A CONSTITUIÇÃO DE UM LABORATÓRIO EM CIÊNCIAS HUMANAS DE "INSPIRAÇÃO MARXISTA" \\ E A POSSIBILIDADE DE FORMULAÇÃO DE UMA CONCEPÇÃO CRÍTICA RADICAL PARA A FORMAÇÃO DE EDUCADORES
}

\author{
Cláudia Lino Piccinini \\ Rosa Maria Corrêa Neves ${ }^{2}$
}

Resumo: Neste artigo, narramos a implantação do Laboratório de Estudos Marxismo e Educação (LEME) ${ }^{3}$. Partimos dos primeiros elementos de sua criação, como a construção de propostas de formação de pedagogos e educadores ambientais, passamos pelos caminhos trilhados na elaboração de uma problemática inicial de pesquisa e na sua reformulação com base na práxis teórico-política e nas derrotas no campo das disputas institucionais e, por fim, chegamos aos resultados e caminhos colocados pela crítica teórica e acadêmica. As categorias luta de classes e consciência se desdobram em novos estudos que ajudam a pensar a organização e a construção das mudanças socioambientais necessárias ao futuro próximo e à formação dos educadores.

Palavras-chave: marxismo e educação, formação, educação ambiental crítica.

Abstract: In this paper, we report the implementation of the Marxism and Education Study Laboratory (LEME). We started from the first elements of its creation, including the formulation of proposals for training educators and environmental educators, then we go through the paths taken in the preparation of an initial research problem and its reformulation based on the theoretical and political praxis and defeats in the field of institutional disputes, and, finally, we present the results and possibilities expressed by the academic and critical theory. The categories of class struggle and consciousness allow new studies that help thinking about the organization and construction of socioenvironmental changes needed for the near future and teacher training.

Keywords: marxism and education, training, critical environmental education.

\footnotetext{
${ }^{1}$ Faculdade de Educação / UFRJ. Contato: clpiccinini@gmail.com

${ }^{2}$ Faculdade de Educação / UFRJ. Contato: rosamcneves@gmail.com.

3 Agência Financiadora: FAPERJ (2008-2010)
} 


\section{O significado de “marxismo e educação" na formulação de um laboratório de estudos}

O Laboratório de Estudos Marxismo e Educação (LEME) resultou da iniciativa de um grupo de professores em Licenciatura Normal Superior, ingressos por concurso público em 2005, no Instituto Superior do Estado do Rio de Janeiro (ISERJ), que cedo se constituíram para estudos e discussões sobre formação de professores. Entre muitos obstáculos a uma ação efetiva de ensino superior, o Grupo identificou insuficiência material e inconsistência da atividade de produção de conhecimento. Esta inconsistência, entretanto, não era fato isolado deste Instituto mas próprio de todo o ensino superior desenvolvido no âmbito da instituição a que se vincula até os dias atuais, a Fundação de Apoio à Escola Técnica, FAETEC, que sustenta um ensino superior de modo bastante precário não apenas no que toca à pesquisa, mas ao próprio ensino, extensão, além de uma organização política bastante problemática.

Especificamente o Curso Normal Superior do ISERJ, de seu início, em 1998, até 2005, foi avaliado tanto por uma comissão de seus próprios docentes quanto por outra, do Conselho Estadual de Educação. Ambas identificaram uma série de problemas, alguns deles ainda sem solução. Na busca de superação de parte desses problemas, o engajamento de integrantes do grupo, centrados em uma análise e exposição de práticas viciadas e pela proposição de determinados encaminhamentos, foi constante e decisivo para uma alteração nos debates e ações institucionais. Dentre as iniciativas, destacamos a proposição de uma Licenciatura em Pedagogia e de um Curso de Pós-Graduação Lato sensu em EA, ambos orientados por uma "inspiração marxista". O sentido pedagógico central dos projetos da Licenciatura e o da pós-graduação Lato sensu em Educação Ambiental ${ }^{4}$ foi "propiciar condições de reconhecimento da consciência de classe e da categoria profissional do educador".

$\mathrm{Na}$ dinâmica do Instituto, algumas ações tiveram efeitos politicamente virtuosos, como a mobilização de estudantes do ensino superior em busca de amplas reformas e a extinção progressiva da problemática Licenciatura em Normal Superior. Um outro resultado bastante significativo foi a aprovação de auxílio financeiro para instalação de um Laboratório de pesquisas via edital da FAPERJ - o Laboratório de Estudos Marxismo e Educação. A expectativa do grupo era, de um ponto de vista material, criar condições efetivas para pesquisa, ensino e extensão, inclusive para os licenciados. Sua temática central era a formação de professores, com vistas à "emancipação da classe trabalhadora" e formulou como objetivo geral de sua pesquisa original, "verificar a possibilidade de formular uma concepção crítica radical da formação do professor da educação

\footnotetext{
4 O curso tinha por objetivos: (i) aprofundar a compreensão sobre a realidade socioambiental do Brasil e do mundo identificando o papel e os limites da educação em sua transformação; (ii) formar educadores ambientais para articular, planejar e desenvolver programas e propostas pedagógicas críticas de Educação Ambiental; (iii) contribuir para a construção do conhecimento em Educação Ambiental.
} 
básica, diante do marco educativo legal". Metodologicamente orientava-se por uma unidade e máxima interlocução possível entre teoria e ação política (cultural e pedagógica), no que a concretização da Licenciatura em Pedagogia seria decisiva. Questões político-pedagógicas advindas da licenciatura em curso seriam problematizadas em núcleos de pesquisa, estrutura que comportaria docentes, discentes, além de outros profissionais do ISERJ ou de outras instituições. Tais questões significariam a superação de uma produção teórica idealista e abstrata, o que pareceu acertado em face de uma fragilidade teórica do campo da educação. Tendo sido aprovada em assembléia geral do ensino superior, o que entendemos como uma vitória, houve também derrotas, que iniciaram pela cassação da proposta do Curso de Licenciatura em Pedagogia, pelos conselhos institucionais do ISERJ e pela FAETEC, esta, interessada em propor uma Licenciatura em Pedagogia única para toda a rede de ensino superior.

A cassação, abrupta, significou um golpe nas pretensões pedagógicas e teóricas do LEME. Foi também imediatamente problematizada pelo grupo que identificou rejeições a Licenciatura aprovada, ainda no desenrolar de suas discussões, ocorridas no ISERJ. Havia uma difusa rejeição ao marxismo e às vésperas da submissão da síntese da proposta em assembléia geral, manifestação explícita e contrária ao objetivo geral da proposta curricular, como antes dissemos, "propiciar condições de reconhecimento da consciência de classe e da categoria profissional do educador". Dado que a objeção não se aprofundou nem foi seguida de proposta contrária ou alternativa, supomos que a rejeição dizia respeito a algumas manifestações enunciadas nos Seminários de discussão da proposta, em especial, identificação de marxismo a economicismo e a ineficácia teórica da categoria classe social no capitalismo contemporâneo. A "experiência da derrota" da proposta pedagógica, e a forma violenta pela qual se manifestou, nos conduziram à percepção de um afastamento entre a identificação como "críticos" de seus adversários e suas práticas institucionais e também a algumas indagações. Por que, em um campo tradicionalmente crítico como a educação, manifesta-se uma rejeição explícita à considerações a respeito de classe, de consciência de classe? A questão ganha acento uma vez que podese supor, por um corte geracional, que boa parte dos signatários do contramanifesto, ao menos os pedagogos, formou-se no esteio das "pedagogias contrahegemônicas". Tais indagações seriam relativas, no plano político, a distintas soluções para tensões entre estado, classe social e educação?

No plano teórico, o golpe afetou o LEME. Se o objetivo geral da pesquisa era, como antes dissemos - "verificar a possibilidade de formular uma concepção crítica radical da formação do professor da educação básica, diante do marco educativo legal" - teve de ser redirecionado. 


\section{Críticas ao marxismo, auto-crítica e novos objetos na relação estado, classe social e educação}

A hipótese da pesquisa a ser investigada na instalação do Laboratório já era problematizada no próprio projeto inicial. Alguns autores sustentavam sua possibilidade de afirmação, como Kuenzer (2002), ao tratar de uma possibilidade de re-significação crítica da noção de competência, e Saviani (2005), na defesa de uma pedagogia politécnica. Já identificávamos, porém, polêmicas sobre o conceito de politecnia, em Nosella (2009), além de posição totalmente contrária às competências pedagógicas profissionais voltadas à luta contra o capital, em Rodrigues (2007).

Se no plano teórico, encontrávamos elementos para confirmação de nossa hipótese, hoje ponderamos que esta expectativa pode ter sido menos teórica que afetiva, já que forjada no calor da discussão e apoios recebidos por ocasião da aprovação da proposta curricular da Licenciatura em Pedagogia. No caso de nossa ação política, diga-se, circunstanciada às relações que estabelecemos e nas quais nos encontrávamos, a negação da hipótese foi peremptória. Em decorrência, a problematização teórica da hipótese se deu também em função da mudança política em que nos encontrávamos, e que ainda hoje afeta os professores que permanecem na instituição. Na pesquisa iniciada (2007-2008), nos exigimos um aprofundamento e elucidação das tradições e circunstâncias históricas que sustentaram a hipótese inicial e seu posicionamento contrário, seja no seio do marxismo, seja na apropriação do marxismo pelo pensamento educacional brasileiro.

Dessa forma, foram desenvolvidos estudos: (i) sobre o hibridismo da apropriação do marxismo por tradições de pensamento e suas circunstâncias históricas: historicismo, estruturalismo e humanismo do século XX; (ii) críticas ao humanismo e ao reformismo, prioritariamente no campo da educação brasileira contemporânea; (iii) o debate sobre a atualidade da Ideologia Alemã.

No estudo e desenvolvimento destas questões, algumas conclusões provisórias foram apontadas. Sobre marxismo, desde sua explicitação como referência para a proposta da Licenciatura em Pedagogia, reconhecíamos a dimensão polêmica do termo, dado que abriga leituras com profundos desacordos seja no plano analítico, seja no plano das práticas políticas. Da introdução dessa proposta, consta a seguinte afirmação "A tradição de Marx, de crítica ao capital, ganhou temas e interpretações distintas porém pode-se afirmar que todos os marxismos têm em comum um traço que julgamos necessários ressaltar - a crítica à sociedade liberal e ao que dela resulta em termos da sociabilidade e da individualidade." A imprecisão do termo é corroborada em outras leituras a que nos dedicamos. Portugal (2008, p. 9), por exemplo, afirma:

Não se pode afirmar sobre a existência de uma visão unificada do que vem a ser o marxismo no debate intelectual contemporâneo: a partir do legado teórico e político de Karl Marx e Friederich Engels 
- e de diferentes e divergentes leituras em torno de sua obra -, o marxismo tem-se configurado, no decorrer de sua história, como um vasto e heterogêneo campo de produção de conhecimento e de lutas sociais, com concepções muitas vezes distintas e divergentes entre si. Em relação a inúmeras questões importantes, constituindose mais como um campo de disputas e divergências do que propriamente unificado.

Handfas (2006) também nos mostra uma das controvérsias da interpretação e atualização do pensamento de Marx, no pós-guerra ligadas à luta pelo socialismo. Colocavam-se questões epistemológicas: filósofo ou cientista? humanista ou materialista histórico? continuidade ou ruptura no pensamento de Marx? ruptura a partir de que categorias, em quais obras? Numa outra direção, um estudo iniciado no LEME, nos apontava a possibilidade de identificação, na história das idéias marxistas no século $\mathrm{XX}$, de categorias próprias do historicismo, do estruturalismo e do humanismo.

Destas contribuições, nos resta a compreensão de que se dizer marxista é bastante ousado, em função da luta empreendida pela revolução socialista por diversos partidos e no seio de movimentos sociais, ao longo dos séculos XIX e $\mathrm{XX}$, porém também bastante impreciso dado que nestes mesmos séculos, tanto o pensamento de Marx e de Engels foram re-significados, com resultados drásticos para movimentos revolucionários, quanto a própria orientação revolucionária e a categoria de classe perdeu terreno no campo das lutas sociais e no plano teórico. E o que pode então significar ser marxista no campo da educação brasileira contemporânea? Nossas conclusões não são originais mas expõem nosso entendimento a partir do início de debate com alguns autores.

A autora defende que, por circunstâncias históricas determinadas, a apropriação do marxismo no pensamento educacional brasileiro, deriva em alguns equívocos, dos quais destacamos um: a autonomia do campo educativo (p.9). A tese da educadora é de que remanesceriam como quadro de referência da conformação do pensamento marxista no campo da educação, elementos teóricos abstratos, filosóficos do pensamento de Marx, como a noção de homem e trabalho. No que afetam a prática educativa, tais "resquícios" enfatizariam a escola, sob a lógica do capital, como instituição em que "seria possível superar todos os problemas da sociedade" (HANDFAS, 2006, p. 98).

Numa direção semelhante, ao criticar a apropriação do marxismo no campo da educação, porém na contemporaneidade, Portugal (2008) defende a tese de que vige uma opção política pelo reformismo. A autora, apesar de identificar no plano epistemológico, uma correta distinção entre os marxistas que investigou entre economia, política e ideologia, ressente-se de uma correta análise histórica de desafios para uma educação socialista. Permanecer no terreno do neoliberalismo, nas críticas do e ao neoliberalismo, para pensar educação, significa orbitar "pelas mudanças contextuais e aparentes do modo de produção capitalista" (p. 15), o que obscurece a dinâmica entre classes sociais. A autora 
propõe como necessário para a produção do conhecimento da realidade educacional brasileira contemporânea uma análise histórica à luz da teoria do imperialismo de Lênin (1979), mostrando que já há ensaios em nesta direção.

Dessas leituras, nos parece problemático o obscurecimento no seio do marxismo contemporâneo, em particular nos meios acadêmicos, da necessidade de um movimento revolucionário para transformação das relações de produção capitalistas, no que se inclui de forma bastante incisiva o debate sobre a exploração dos recursos socioambientais.

\section{As experiências do LEME e a questão socioambiental: o feito, o a fazer e as novas indagações}

Como exposto anteriormente, o primeiro movimento de construção de uma unidade teórico-prática (articulação primordial da teoria com a prática sócio-política para a formação de educadores) se deu através da elaboração de uma proposta pedagógica para a formação de professores, em meados de 2007. Nesta proposta, desdobrada também em um curso de pós-graduação em Educação Ambiental Lato sensu, estabelecemos objetivos e compromissos com a transformação social, ambiental e com novas formas de pensar a realidade, em primeira instância, a partir das elaborações teóricas do materialismo histórico de Marx e Engels (Manuscritos econômico-filosóficos e A Ideologia Alemã).

Em uma das pesquisas realizadas (PICCININI, 2009), buscamos entender como educadores ambientais traçaram seus caminhos de formação e de atuação profissional. Interessava-nos saber, a partir da perspectiva de intelectual orgânico de Gramsci (1995) e de estudos recentes do campo (CARVALHO， 2002; GUIMARÃES， 2004; LAYRARGUES， 2002; LOUREIRO, 2007; NOVICKI, 2003; TOZONI-REIS, 2007), se pela via da Educação Ambiental nas condições sociais, culturais e econômicas da contemporaneidade está se formando uma nova intelectualidade no campo educacional. Pensávamos, a partir da questão central elaborada pelos estudos do LEME - se uma pedagogia radical é possível - ampliada na perspectiva socioambiental, se a EA se constitui como pólo de resistência social ao modelo capitalista em curso.

Tendo como material empírico memoriais de 22 educadores ambientais, textos elaborados e escritos pelos personagens centrais da pesquisa, onde detalham os percursos de formação e de atuação no campo profissional, problematizou-se as diversas trajetórias formativas e o trabalho realizado ao longo de suas trajetórias profissionais buscando pensar tal problemática.

A pesquisa fundamentou-se em duas faces indistintas e complementares. A primeira penetrou no universo de formação de educadores ambientais que trazem contribuições para compreender os caminhos e opções rumo a gênese de um corpo profissional - o educador ambiental. A segunda se propôs a analisar percursos e práticas de atuação destes profissionais que, constituídos também no universo do trabalho, se propõem à tarefa de transformação socioambiental. 
Tanto a formação, quanto o trabalho foram compreendidos como categorias gerais para uma visão ampla da realidade concreta.

Ao discutir a categoria trabalho pretendíamos conhecer as bases das relações de produção que condicionam a formação e o trabalho de educador ambiental nas suas várias possibilidades e que diretamente conformam a sociedade onde se inserem. Pois, o acirramento das relações de produção no universo do trabalho tem alterado a vida social, política e espiritual dos trabalhadores. O que deveria fundamentar a humanidade, a realização intelectual e a consciência, se transformaaquilo que Marx denominou de 'trabalho alienado' (MARX, Manuscritos econômico-filosóficos). Auxiliando no processo de alienação e de exclusão do trabalhador, a educação ${ }^{5}$ passa a ser apenas um instrumento de dominação para que "os pobres se ajustem às mudanças sociais próprias do capitalismo" (LEHER, 2005). Transformada em mercadoria a educação tem perdido seu potencial crítico e transformador. Para Marx, o objetivo histórico da educação se contrapõe a uma formação unilateral, utilitarista, coisificada, que serve unicamente aos propósitos do capital, isto é, de tornar o humano insumo para o próprio circuito do capital, de adestrá-lo às disposições ideológicas do capital.

A partir do diálogo com as fontes e da constituição de uma visão de conjunto das narrativas, foi possível problematizar as rotas de formação dos educadores ambientais e a constituição de um grupo sócio-profissional, a partir das informações como: (i) o discurso de entrada na carreira, as escolhas e ações de ingresso na formação inicial, na pós-graduação e no mundo do trabalho, (ii) os loci de atuação; (iii) a prática política e a função assumida no grupo; (iv) os seus interlocutores no processo de profissionalização; (v) o projeto de sociedade que buscam alcançar; (vi) as concepções que vão sendo reveladas sobre educação/EA, sobre ser educador ambiental etc. Também foi possível verificar e analisar o aparecimento das contradições e críticas aos problemas vivenciados em seus cotidianos de ação, principalmente em relação à formação inicial, os limites das ações de trabalho com a EA, a relação teoria e prática, as limitações e avanços ao longo do próprio processo formativo, as dificuldades de atingir os ditos "princípios da EA" e as contradições implicadas na relação trabalho e formação. Ou seja, a profissionalização está marcada pelos históricos dualismos do campo - disciplinar/interdisciplinar, do discurso teórico/da prática, da graduação/da pós-graduação, de perspectiva crítica/ tradicional.

Caminhando pelas etapas formativas - da graduação à pós-graduação - e pensando as relações e contradições estabelecidas pelo mundo do trabalho foi possível destacar o que intitulamos de "discurso de construção da consciência". Existe um registro discursivo dominante que desconhece (ou não aponta) os limites do trabalho da educação e da EA. A visão manifesta de EA está vinculada

${ }^{5}$ Referimo-nos à educação em todos os níveis, como também à ciência, reconhecendo que a Universidade, que congrega formação e produção do conhecimento está amplamente inserida no referido processo de mercantilização (OLIVEIRA, 2005). 
com a "preocupação" de conscientizar os educandos para a necessidade de um outro entendimento da relação homem-natureza. Mas esta "preocupação" permanece alienada da praxis de alguns indivíduos. Já em outros será transposta para outra dimensão, com a realização de ações que buscam a transformação concreta da sociedade, questionando a relação homem-natureza.

Compreendemos que a intenção de poder mudar o próprio rumo e o mundo através do conhecimento e da educação se relaciona à idéia de busca de um ideal que se consolida através da construção de uma tradição ideológica, muito presente entre os educadores ambientais e que reflete, através dos argumentos apresentados, a busca de um objetivo comum, onde a educação se apresenta como recurso necessário para a melhoria da sociedade e para a superação da crise socioambiental. Porém, se esta perspectiva acentua o papel do profissional educador, por outro lado reflete o que Sacristán (1999) chama de "ocultação ideológica", de caráter consciente ou não, e que redunda na "biperresponsabilização" (idem) atribuída aos educadores pela sociedade e, algumas vezes introjetada e assumida como verdade por muitos. Há um idealismo presente nas vozes destes educadores e que limitam suas narrativas quando conectadas à realidade.

\section{Conclusões e contribuições para o campo da educação ambiental}

Para efeito de novos estudos no campo da educação, e na direção de combater mistificações, ilusões e idealismos que parecem conformar a identidade de educadores, nossa identidade, identificamos a vitalidade de A Ideologia Alemã, de Marx e Engels, obra de inflexão segundo Althusser (1999). Consideramos também uma tarefa para o campo da educação investir nas críticas formuladas pelos autores que examinamos - humanismo e reformismo.

No que se refere aos desdobramentos das pesquisas realizadas (NEVES et al., 2008; PICCININI, 2009; TONÁCIO \& PICCININI, 2010), é nossa intenção aprofundar análises em torno da categoria "conscientização" e da atualização do conceito de classe em Marx, de onde surgem indagações - ações de EA fora do aparelho de estado possuem potencial real de crítica e de transformação da realidade socioambiental? Em caso afirmativo, estariam suas ações embasadas por uma "consciência de classe"?

Assim, desafiadas a pensar a educação/ EA incluímos a possibilidade de desdobramento do debate acerca da atualização do conceito de classe em Marx, para se chegar à problemáticas referentes a luta de classes e consciência de classe. Neste sentido, pretendemos romper com o idealismo e estruturar uma forma epistêmica que considere historicamente as relações dos homens entre si e dos homens com a natureza, o que nos parece poder contribuir para o campo da educação ambiental em uma perspectiva crítica. 


\section{Referências}

ALTHUSSER, Louis. Sobre a reprodução. Petrópolis: Editora Vozes, 1999.

CARVALHO, Isabel C. de Moura A Invenção Ecológica: Narrativas e Trajetórias da Educação Ambiental no Brasil. Porto Alegre: Ed. Universidade/ UFRGS, 2002.

ENGELS, Frederic Sobre o papel do trabalho na transformação do macaco em homem 1876. Disponível em: <http://www.insrolux.org/>. Acesso em: 13 de fevereiro de 2008.

GRAMSCI, Antonio. Os intelectuais e a organização da cultura. $9^{\mathrm{a}}$ ed. RJ: Civilização Brasileira, 1995.

GUimarães, Mauro. A formação de Educadores Ambientais. Campinas, SP: Papirus, 2004.

HANDFAS, Anita. Uma leitura crítica das pesquisas sobre as mudanças nas condições capitalistas de produção e a educação do trabalhador. (Tese de Doutorado), Programa de Pós-Graduação, Universidade Federal Fluminense, Niterói, 2006, 152p.

KUENZER, Acácia. Conhecimento e competências no trabalho e na escola. IN: Boletim Técnico do SENAC. Rio de Janeiro: Edt SENAC, v.28, n.2, p.03-11, 2002.

LAYRARGUES, Phillipe P. A crise ambiental e suas implicações na educação. IN: QUINTAS, J.S.(org.) Pensando e Praticando a EA na gestão do meio ambiente. Brasília: IBAMA, 2002.

LEHER, Roberto Educação e tempos desiguais: reconstrução da problemática trabalho-educação. Disponível em: <http://www.educacaoonline.pro.br/ $>$ Acesso em: 27 fev. 2005.

LENIN, Vladimir I. O Imperialismo: fase superior do capitalismo. São Paulo: Global, 1979.

LOUREIRO, Carlos F. (org.) A questão ambiental no pensamento crítico: natureza, trabalho e educação. Rio de Janeiro: Quartet, 2007.

NEVES, Rosa M.C. et al. Perspectiva crítica da formação de trabalhadores da educação. IN: VII Seminário REDESTRADO. Buenos Aires, 2008.

NOSELLA, Paolo. Compromisso político e competência técnica: relendo Gramsci. Disponível em: <http:www.artnet.com.br/gramsci/arquiv.332.htm> Acesso em: 30 jan. 2009.

NOVICKI, Vitor. Abordagens teórico-metodológicas na pesquisa discente em Educação Ambiental: programas de pós-graduação em educação do Rio de Janeiro (1981-2002). IN: 26 ${ }^{\mathbf{a}}$ Reunião Anual da ANPED, Minas Gerais: Caxambu, 2003.

OLIVEIRA, Marcos B.Ciência: força produtiva ou mercadoria? IN:Crítica Marxista. RJ:Revan, n.21, 2005. 
PICCININI, Cláudia L. A formação e o trabalho dos educadores ambientais: um diálogo com a memórias. Rio de Janeiro: Departamento de Educação, PUC-Rio (Tese de Doutorado), 2009, 269p.

PORTUGAL, Adriana D. Considerações acerca da atual produção de conhecimento de inspiração marxista em Filosofia da Educação: uma perspectiva marxista. Rio de Janeiro: PROPED, UERJ (Dissertação de Mestrado), 2008, 111p.

RODRIGUES, Daniel Álvares. A impossibilidade da ressignificação das competências numa perspectiva marxista. $\mathbf{3 0}^{\mathbf{a}}$ Reunião Anual da ANPED, Minas Gerais: Caxambu, 2007.

SACRITÁN, J. Gimeno Consciência e acção sobre a prática como libertação profissional dos professores. IN: NÓVOA, A. (org.) Profissão professor. Porto-Portugal, Porto Editora, 1999.

SAVIANI, Dermeval. A pedagogia histórico-crítica: primeiras aproximações. 9 ed. Campinas: Autores Associados, 2005.

TONÁCIO, Glória de Melo \& PICCININI, Cláudia L. Movimento de estudantes e professores no processo de criação do curso normal superior no Instituto Superior de Educação do Rio de Janeiro e a sua adequação em curso de pedagogia. IN: Seminário Internacional Gramsci e os Movimentos Sociais. NUFIPE, UFF, 13 a 16 /set/2010. Disponível em <http://www.nufipeuff.org/trabalhos_apresentados.html\#paineltematico29>

TOZONI-REIS, Marília F.C. Contribuições para uma pedagogia crítica na educação ambiental: reflexões teóricas. IN: LOUREIRO, C. B. F. (org.) A questão ambiental no pensamento crítico: natureza, trabalho e educação. Rio de Janeiro: Quartet, 2007. 